\title{
Gland Loss
}

National Cancer Institute

\section{Source}

National Cancer Institute. Gland Loss. NCI Thesaurus. Code C82989.

A morphologic finding indicating the partial or complete loss of a gland structure. 